Rudolf Ornstein *

1. Introdução. 2. Definiçōes : conceitos gerais. 3. Avaliação das

existências. 4. Demonstraçôes financeiras e a determinação do rédito. 5. A determinação do preço de venda pelo custeio direto. 6 . Outros aspectos da aplicacão do custeio direto. 7. Conclusōes.

\title{
Aspectos atuais do método do custeio direto
}

Há mais de 10 anos foi publicado nesta revista um artigo de W. Schoeps sôbre o método de custeio direto, ${ }^{1}$ em que 0 autor examina as características dêste sistema de custos, salientando as vantagens do método para o processo da tomada de decisões e manifestando a expectativa de que o método encontre aplicação mais difundida, no sentido de um aprimoramento na gestão das emprêsas. Naquela época, o método do custeio direto ainda constituía novidade para muitos contabilistas e administradores de emprêsas do Pais; hoje um grande número de decisões empresariais estão sendo tomadas, quase automàticamente, em têrmos de custeio direto, sem que as pessoas se confessem adeptos absolutos do sistema.

Entretanto, a penetração total do nóvo método, esperada pelos seus proponentes, não se realizou ainda nestes últimos 10 anos. Os empecilhos de caráter fiscal continuam existindo no mundo inteiro e a resistência doutrinária, por parte de muitos contadores da escola tradicional, opõe-se à adaptação da contabilidade escritural ao nôvo método. Nas revistas especializadas americanas e européias são publicados seguidamente artigos que defendem os vários pontos de vista, examinando aplicações e conseqüências do método. A controvérsia continua ${ }^{2}$ mas, com o correr do tempo, torna-se claro que na medida em que os conceitos quantitativos da "contabilidade gerencial" (management accounting) são adotados na vida empresarial, os métodos do custeio direto e da análise marginal prevalecerão cada vez mais como instrumentos decisórios.

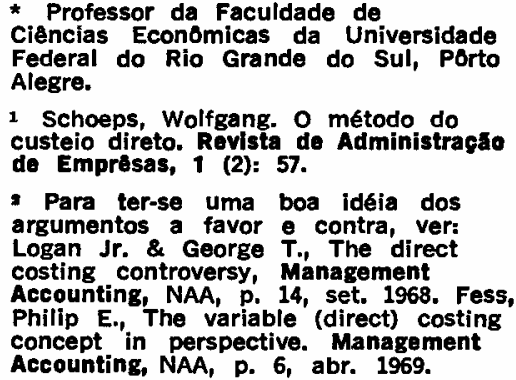


Neste artigo pretende-se apresentar a situação atual da utilização do custeio direto nas suas áreas principais, redefinindo-se alguns conceitos que sofreram alterações e clarificações no decorrer dos anos, sem contudo entrar demasiadamente no campo das argumentações teóricas.

\section{DEFINIÇŌES E CONCEITOS GERAIS}

Define-se como "custo direto" todo o custo, diretamente mensurável em quantidade e valor, causado pela produção e/ou venda de um produto. (Esta definição tem um sentido limitado pelo emprêgo do têrmo "produto"; veremos mais adiante que existe uma definição mais ampla do conceito).

0 custo direto do produto compõe-se conseqüentemente da matéria-prima, dos salários diretos, do impôsto sôbre circulação de mercadorias (ICM) a pagar, comissões percentuais sôbre venda e mais algumas parcelas, tôdas elas rigorosamente proporcionais ao número das unidades transacionadas do produto.

Verifica-se que êstes custos diretos se agrupam em duas categorias: os da produção e os custos (ou despesas) diretos da venda.

Surpreendentemente, o método do "custeio direto" não se refere aos custos diretos. Para definir o custeio direto é necessário empregar um outro conceito, o do "custo variável", ou seja, aquêle custo que depende do nível de atividade da emprêsa. 0 custo variável é composto de todo o custo direto e de mais algumas espécies de custos indiretos como, por exemplo, o consumo de energia, de combustivel, ferramentas, manutenção, etc.; todos são custos causados pela produção, porém não mais mensuráveis diretamente em relação ao produto.
R. W. Kates, recapitulando as explicações fornecidas sôbre o custeio direto no Research Report da National Automobile Association (NAA) referente ao assunto, opina que a definição mais simples envolve "todos os custos que podem ser diretamente associados com a produção, distribuição e as operações do marketing do produto" (tradução do autor). ${ }^{3}$

\section{O teorema básico do custeio direto afirma que o custo dos produtos se compõe exclusivamente do somatório dos seus custos variáveis.}

Os custos fixos, o segundo grande grupo dos custos, são considerados como custos de um período, ou seja, do tempo percorrido da existência da emprêsa, não devendo ser apropriados ao produto.

Pelo exposto torna-se evidente que seria mais correto falar do método do "custeio variável" em lugar do "custeio direto", mas o têrmo enganador persiste, especialmente na literatura norte-americana. Os autores europeus, tendo em vista que o conceito do custo variável quando aplicado à unidade do produto corresponde pràticamente ao "custo marginal" da teoria econômica, falam de preferência do "custeio marginal" (marginal costing, Grenzkostenrechnung, comptabilité marginale etc.). P. Occhipinti emprega o têrmo "costo primo variabile",4 enquanto que $M$. Moisson substitui a definição dos custos diretos pelo têrmo "custos específicos". 5

\section{Existem ainda outras} nomenclaturas que sòmente contribuem para tornar ainda maior a confusão semântica. Para fins do presente estudo será conservado o têrmo "custeio direto" para caracterizar o método que aplica ao produto (ou serviço prestado) sòmente os custos causados pelo mesmo produto e diretamente identificáveis com êle. Trata-se, para usar uma conceituação muito clara de G. Shillinglaw de todos os custos que seriam evitados se o produto não tivesse sido fabricado (avoidable costs). ${ }^{\circ}$

Històricamente, o método do custeio direto data oficialmente do ano de 1936, quando foi pela primeira vez usado por $J$. Harris. A idéia de eliminar os custos fixos do custo do produto, na realidade, já remonta a épocas anteriores. ${ }^{7}$

Em oposição ao método do custeio direto encontra-se o método clássico e tradicional do "custeio integral" (também custo completo ou total), ${ }^{8}$ pelo qual todos os custos da emprêsa são apropriados ao produto. Os custos fixos são imputados ao produto mediante um dos muitos métodos calculatórios de alocação ou rateio. É justamente a arbitrariedade. dêstes procedimentos da imputação, em conjugação com o fato de que os custos fixos ocorrem, na maioria das vêzes, independentemente do produto, que sempre causou certa resistência contra os métodos do custeio integral, assim como provocou dúvidas quanto à veracidade dos resultados calculatórios.

Convém mencionar, aqui, que a maioria dos autores que tratam do assunto, especialmente os norte-americanos, costumam confrontar o "custeio direto"

\footnotetext{
3 Kates, R. W. Direct costing. Management Accounting, ICWA, p. 13, London, jan. 1970.

- Occhipinti, P. Direct costing una moderna técnica del rilevazione $e$ controllo dei costi aziendali. Milano, Etas Kompass, p. 49 e seg.

- Moisson, M. Pratique de l'établissement du prix du revient. Paris, Les Editions d'organisation, 1963.

- Shillinglaw, G. Cost accounting analysis and control. Homewood, III. Irwin, 1967. p. 58.

7 Para uma breve história do desenvolvimento da teoria, ver: Occhipinti, P. op. cit. p. 62.

- A terminologia em português ainda nao está bem definida. $O$. Koliver usa o térmo "custeio global" para caracterizar o método tradicional em: Apontamentos sobre contabilidade de custos. Porto Alegre, Editóra Staff, 1968. p. 22, v. 1. Em ingless fala-se sempre de full cost, em alemão de Vollkosten, em italiano costi complessivi, em francés coat complet, etc.
} 
com o "custeio por absorção".

Êste procedimento não é perfeitamente correto, visto que o custeio por absorção representa sòmente uma das muitas formas do custeio integral. No custeio por absorção, que realmente é o método mais difundido nos Estados Unidos, os custos fixos da produção são imputados ao produto com base em um volume de produção preestabelecido (volume normal). Na maioria das emprêsas brasileiras o procedimento e diferente: os custos fixos são apropriados em base da produção efetiva, mediante coeficientes de suplementos seletivos. Existem outras formas do sistema do custeio integral, tendo todos êles como característica essencial a inclusão de custos fixos. Resumindo a dicotomia, têm-se:

Custeio integral: inclusão de custos fixos no custo do produto.

Custeio direto: exclusão de custos fixos no custo do produto.

$\mathrm{Na}$ terminologia do custeio direto, entende-se por "contribuição marginal" a diferença entre o custo do produto e seu preço de venda. Ocasionalmente empregam-se têrmos diferentes como "renda marginal", "contribuição de cobertura", "margem de contribuição" ou simplesmente "contribuição".

No custeio integral, o conceito paralelo da diferença entre preço e custo seria o rédito do produto, ou seja, o lucro, no caso normal de um rédito positivo.

O somatório das contribuições marginais de todos os produtos vendidos forma a "contribuição total" da emprêsa, cujo montante deve ser suficiente para cobrir todos os custos fixos da emprêsa e ainda deixar um saldo para o lucro. Tôda a filosofia do custeio direto resume-se na idéia de que não se deve tentar isolar os custos fixos e os lucros dos produtos individuais; as contribuições fornecidas pelos diversos produtos (ou atividades) fluem para um reservatório comum (a contribuição total), do qual a emprêsa retira os custos fixos totais; o lucro restante é comum, não identificável com qualquer produto ou segmento da emprêsa.

Esta maneira de raciocinar, que à primeira vista pode parecer como nada mais do que um simples expediente da técnica contábil, conduz na realidade a uma profunda: reorientação no pensamento empresarial; em vez de maximizar o rédito, as decisões administrativas agora procuram maximizar a contribuição total. Como critério decisório o sistema do custeio direto produz resultados diversos da sistemática anterior, porém, resultados mais condizentes com os fatos econômicos, dando maior flexibilidade à administração empresarial em face das constantes modificações da estrutura de custos e réditos. 0 custeio direto, quando adotado como base do sistema de custos da emprêsa, exerce sua influência em tôdas as áreas administrativas, quer seja nos procedimentos contábeis, na apuração de resultados, na política de preços, no planejamento da produção, ou no orçamento empresarial, etc.

Serão examinados, neste artigo, os reflexos do método em três áreas onde êles se fazem sentir com especial vigor e em tôrno dos quais ainda giram as controvérsias mais acesas entre os adeptos e os oponentes do método.

Trata-se dos seguintes problemas:

a) Inventário: avaliação das existências de produtos.

b) Forma das demonstrações financeiras e determinação do rédito da emprêsa. c) Política de preços de venda e método calculatório.

Admite-se que existam interligações entre os três problemas citados e, sob o aspecto teórico, não deviam ser analisados separadamente. Todavia, para facilitar a formação de uma opinião definitiva, julgamos melhor examiná-los isoladamente. $\mathrm{Na}$ prática, muitas emprêsas usam o método do custeio direto para uma ou outra finalidade, especialmente no campo da tomada de decisões, sem aplicá-lo de forma generalizada em todos os seus registros da gestão.

\section{AVALIAÇAO DAS EXISTENCIAS}

A respeito do problema da inclusão ou não dos custos fixos da produção no valor dos produtos acabados ou em via de elaboração, as opiniões dos teóricos já não divergem tanto quanto ainda acontece nas outras áreas. São poucos os autores que ainda se opõem ao método do custeio direto quando aplicado à avaliação inventarial; a maioria reconhece que a avaliação dos produtos mencionados à base de um valor elevado, resultante da incorporação de parcelas de custo fixo, significa uma antecipação de lucros de um lado e, de outro, uma oneração em dôbro, pelos mesmos custos, no período subseqüente ao levantamento inventarial.

Sorter e Horngren afirmam que "qualquer custo é inventariado sómente sob a condição do mesmo exercer um efeito econômico favorável sôbre os custos futuros esperados ou as receitas futuras" (tradução do autor). ${ }^{9} \mathrm{~W}$. Maennel declara mais categòricamente que "na avaliação é permitido incluir apenas aquêles custos, os quais,

- Sorter, G. \& Horngren, Ch. Asset recognition and economic attributes the relevant costing approach. The Accounting Review, p. 393, jul. 1962. 
em virtude da existência dos estoques referidos serão economizados na continuação das atividades no período futuro" (tradução do autor). ${ }^{10}$

Evidentemente, existem poucos custos fixos que satisfaçam estas condições e que são sujeitos ao desaparecimento em conseqüência da presença de estoques de produtos.
Quando isto ocorrer, é sòmente a prazo muito longo.

A problemática da incorporação dos custos fixos de produção no valor do inventário e a conseqüente influência sôbre os resultados deixam-se

demonstrar por um exemplo em têrmos muito simples.
Custos variáveis de produção:

Custos fixos da produção (depreciação):

(Não há outros custos).

Número de unidades do produto fabricado:

Venda dentro do período:

Preço de venda:
Cr $\$ 5.000,00$

Cr\$2.000,00

1.000 unidades

500 unidades

Cr $\$ 10,00$ por unidade
Consideramos uma emprêsa que dentro de um período (ano) apresenta os seguintes dados:

Obviamente, a emprêsa deve inventariar a quantidade de $\mathbf{5 0 0}$ unidades não vendidas, no fim do ano. Pelo método do custeio integral êste estoque seria avaliado por $\mathrm{Cr} \$ 7,00$ por unidade (7 mil dividido por mil), e, pelo método do custeio direto, excluindo a depreciação, por $\mathrm{Cr} \$ 5,00$ por unidade. Este estoque será, todo êle, vendido no período seguinte, no qual, para simplificar a demonstração, não haverá produção. Observamos a formação do resultado pelos dois métodos (Ver quadro 1).

\section{QUADRO 1}

Custeio integral

Custo variável da produção

Depreciação

Custo total $(1.000$ unid. $\times 7,00)$

Receita da venda (500 unid. $\times 10,00)$

Aumento do estoque (500 unid. $\times 7,00)$

Diminuição estoque (500 unid. $\times 7,00)$

Ingresso total

Resultado do período:

(Ingresso menos custo)

Custeio direto

Custo variável da prođução

Depreciação

Custo total:

Receita da venda (500 unid. $\times 10,00$ )

Aumento do estoque (500 unid. $\times 5,00)$

Diminuição do estoque (idem)

Ingresso total:

Resultado do período:

\section{Ano em Crs}

$\begin{array}{rr}5.000 & - \\ 2.000 & 2.000 \\ 7.000 & 2.000 \\ 5.000 & 5.000 \\ +3.500 & - \\ -3.500 \\ 8.500 & 1.500 \\ +1.500 & -500 \\ \text { (Lucro) } & \text { (Prejuízo) }\end{array}$

$$
\begin{array}{rr}
5.000 & - \\
2.000 & 2.000 \\
7.000 & 2.000 \\
5.000 & 5.000 \\
+2.500 & -\overline{2.500} \\
\overline{7.500} & 2.500 \\
+\quad 500 & +500 \\
\text { (Lucro) } & \text { (Lucro) }
\end{array}
$$

\section{$\overline{2.000}$}

O lucro total dos dois períodos, igual a $\mathrm{Cr} \$ 1$ mil, evidentemente, é idêntico nos dois casos, com a diferença de, no caso do custeio direto, haver uma distribuição em partes iguais sôbre os dois anos, enquanto que o custeio integral gera um lucro antecipado e artificial no primeiro ano, compensado por prejuizo no segundo. Esta situação apresenta duas irregularidades: primeiro, fere o princípio de que qualquer lucro deve ser gerado exclusivamente pelo ato de venda (princípio da realização); segundo, dá origem às conhecidas inconveniências financeiras da antecipação de lucros, quais sejam, um aumento no impósto de renda, distribuição de dividendos fictícios, etc. Além disso, pode dar motivo a decisões gerenciais errôneas, assunto que será examinado mais adiante.

0 montante das possíveis distorções na apuração do rédito da emprêsa, em conseqüência da inclusão de custos fixos de produção no valor dos produtos inventariados, depende da proporção entre a produção vendida e a estocada (ou desestocada). 0 aspecto matemático da questão foi exaustivamente estudado por S. Hummel. 110 fenómeno pode ser observado continuamente na vida das emprêsas industriais. 0 que surpreende é o fato de muitos administradores não se darem plenamente conta do efeito que as variações dos estoques, quando avaliados pelo custeio completo, exercem sôbre o comportamento dos resultados periódicos. Reside aqui um dos argumentos mais fortes em favor da adoção do custeio direto para fins de avaliação de produtos prontos $\mathrm{e}$ semi-acabados.

Outro problema, já antigo, que pode surgir em conexão com a inclusão dos custos fixos, aliás fartamente discutido na literatura contábil, é o da

\section{Maennel, W., Volikostenrechnung mit gesonderten Fixkostenbeitraegen.} Zeitschrift fuer Betriebswirtschaft. Wiesbaden, dez. 1967. p. 776.

It Hummel, S. Die Auswirkungen von Lagerbestandsveraenderungen auf den Periodenerfolg - Ein Vergleich der Erfolgskonzeptionen von

Erfolgskonzeptionen von Vollkostenrechung und Direct Costing Zeitschrift fuer betriebswirtschaftlic
Forschung, Colonia fev. 1969. p. 155. 
influência do volume de produção sôbre a parcela dos custos fixos apropriada no custo unitário. Em caso de uma diminuição do volume produzido, o custo unitário apurado em base dos custos atuais subirá e, paralelamente, sobe o valor do inventário. (No exemplo do quadro 1 , uma redução da produção pela metade faria aumentar a parcela da depreciação incorporada para o dôbro e o valor unitário, para fins da avaliação, cresceria para $\mathrm{Cr} \$ 9,00$.

O problema, porém, parece ter hoje sòmente menor gravidade, visto que não existem mais muitos contadores que consintam capitalizar desta forma os custos da capacidade ociosa. A maioria das emprêsas, quando incorpora os custos fixos, utiliza para esta finalidade custos preestabelecidos (custos paramétricos) em base de padrões (standards) ou fundamentados no volume normal de produção ou em um orçamento flexivel.

Mas, mesmo êstes métodos, em particular o custeio por absorção em base de uma produção "normal", podem transformar-se em causas de novas distorções perigosas especialmente quando o volume de produção ultrapassa sensivelmente o volume previsto. ${ }^{12}$

Tôdas as complicações oriundas do emprêgo do custeio integral para o inventário são eliminadas pelo custeio direto, fato êste tàcitamente reconhecido, salvo raras exceções apenas. G. J. Staubus, por exemplo, insiste que, como a capacidade de produzir resulta em custos fixos e como a existência de estoques pode influir no planejamento da capacidade de produção, os custos fixos devem formar parte natural do custo dos inventários. ${ }^{13} 0$ argumento parece de pouca validade já que o planejamento da capacidade exige decisões a longo prazo enquanto que as variações dos estoques representam um fenômeno de curto prazo.

Resumindo o que foi exposto nos parágrafos precedentes, chega-se à conclusão de que, em teoria, não existem motivos contrários à introdução do custeio direto como método de avaliação. Entretanto, na prática, a situação é justamente a oposta. A oposição contra o uso do custeio direto para os fins indicados vem de duas direções. O mais importante obstáculo é causado, no mundo inteiro, pelas administrações públicas do impósto de renda. Não podendo ignorar o fato de que o custeio integral fornece valôres mais elevados para as existências de produtos prontos $\mathrm{e}$

semifabricados e que, conseqüentemente, o lucro tributável será mais elevado (ou pelo menos antecipado), as autoridades fiscais, em quase todos os países, levantam barreiras contra o sistema do custeio direto. Nos Estados Unidos, hoje, o fisco parece estar cedendo lentamente, permitindo o método sob certas condições, exigindo especialmente "consistência" na aplicação de qualquer método contábil. ${ }^{14}$ Realmente, na introdução do custeio direto, o maior impacto sôbre o rédito verifica-se no primeiro balanço escriturado, devido à redução do valor das existências; uma vez implantado o sistema nôvo, as diferenças comparativas entre inventários subseqüentes não são mais da mesma magnitude. No Brasil, a atitude das autoridades da Receita Federal ainda não está definida a respeito do assunto; aliás, de forma geral, encontram-se poucas diretrizes firmes referentes à avaliação de produtos manufaturados. Para evitar possíveis complicações, são poucas as firmas brasileiras que se arriscariam a proceder à avaliação de suas existências, sem pelo menos incluir uma fração de custos fixos no cálculo do custo unitário.

A segunda fonte de oposição nasce da atitude negativa dos contadores profissionais, educados pela escola tradicional. Acostumados desde longos tempos a transferir todos os saldos das contas de despesas de produção para as contas de fabricação, êles geralmente resistem a uma sistemática que manda debitar os saldos das contas de custos fixos diretamente a uma conta de rédito. 0 problema ainda é dificultado quando, como geralmente ocorre nas contabilidades clássicas, não existe separação no plano de contas entre custos fixos e variáveis. Esta atitude hesitante em aprovar um sistema de custos que difere essencialmente da contabilidade clássica reflete-se nas publicações oficiais das associações profissionais de contadores, as quais, na melhor das hipóteses, assumem uma posição neutra em face do problema. ${ }^{15}$ Somente na Inglaterra, a Recomendação n. ${ }^{\circ}$ 22, do Institute of Chartered Accountants, afirma quase inequivocamente que o custeio direto fornece resultados mais corretos relativos à avaliação de inventários e a determinação do lucro, em quase todos os casos. Não encontramos nenhuma definição de associações profissionais de outros países sôbre 0 assunto.

A. N. Davidson apela às organizações de contadores para tomarem uma posição definitiva sôbre os méritos do custeio direto "sem consideração da prática fiscal". ${ }^{16}$ A NAA alude à possibilidade de que as firmas

\footnotetext{
12 assunto demonstrado por G. Amerman, em: Facts about direct costing for profit determination. In: Contemporary lasues in Cost Accounting. H. Anton \& P. Firmin, Boston, 1966. p. 151. 1s Staubus, G. J. Direct, Relevant or Absorption Costing. Institute of Business and Economic Research, University of California, Berkeley, 1963. p. 68.

14 Ver, por exemplo, Davidson, A. N. Acceptance of direct costing. In: Management Accounting. NAA, New York, p. 35, mar. 1970.

15 Ver, por exemplo, NA(C)A Research Bulletin, n. 23 e n. 37; AICPA. Research Bulletin; n. 43, etc. publicados nos EUA.

16 Davidson, A. N. op. cit. p. 37.
} 
se convençam das vantagens do custeio direto e executem uma contabilidade paralela, usando o custeio integral para fins externos e fiscais e o custeio direto para os objetivos internos e administrativos. ${ }^{17}$ Sugestões similares também foram emanadas de organizaçס̋es européias. A impraticabilidade e complexidade da condução de dois inventários simultâneos reduz a realização de tais possibilidades para casos especiais, relativamente raros.

No Brasil, o assunto analisado neste parágrafo adquire ainda um aspecto particular em conseqüência da dedutibilidade do lucro tributável de uma certa importância para a manutenção do Capital de Giro Próprio (Decreto-lei n. ${ }^{\circ}$ 401). O custeio integral fornece valôres mais elevados para o inventário $e$, conseqüentemente, para o capital em giro, de maneira que a isenção físcal, que é proporcional a êste último, também se torne maior do que ocorreria no caso de custeio direto. O tributo maior do primeiro método é parcialmente compensado pela dedução mais alta. O montante exato desta compensação depende naturalmente do montante absoluto do rédito tributável.

\section{DEMONSTRAÇ̃̃ES \\ FINANCEIRAS E A DETERMINAÇAOO DO RÉDITO}

Como já foi mostrado no exemplo do quadro 1 , a escolha do método de custeio infiui numèricamente na apuração do rédito periódico. Devido a inclusão ou não de custos fixos no valor inventariado, ocorre uma transferência de lucros (ou prejuízos) de um período contábil para o seguinte. Mas não é êste o fenômeno que será examinado neste item; o que se quer provar agora é que, para fins de contrôle e para a tomada de decisões, o método do custeio direto oferece vantagens distintas em confronto com o custeio integral, sem que isto signifique necessàriamente que os resultados finais, demonstrados pelos dois métodos, sejam diferentes.

Em relatórios de resultados, especialmente para o uso de administradores de nível médio (por exemplo, chefes de departamentos fabris, mestres de produção, etc.), a inclusão de custos fixos não é desejável. 0 objetivo dêsses relatórios é de apresentar dados que possam ser usados como base para decisões relativas ao comportamento dos custos controláveis, ${ }^{18}$ ao nivel do supervisor recebedor do relatório. A maioria dos custos fixos, ou seja, a depreciação do equipamento, o ordenado do próprio supervisor, juros e outros mais, são custos incontroláveis no referido nível, sendo conseqüências de decisões tomadas em nivel hieràrquicamente superior. Nada se ganha, em demonstrar o rédito líquido; o que se exige do departamento ou segmento da emprêsa é que a contribuição seja maximizada dentro do volume de produção

preestabelecido. No mesmo nível da administração média a inclusão de custos fixos no custo unitário do produto, geralmente provoca sòmente erros de interpretação. A relação entre o custo e volume de produção, ou seja, o impacto de uma ociosidade parcial, é muitas vêzes imperfeitamente compreendido. Examinando êste aspecto, W. Wright, autor que dedicou vários estudos aos assuntos do custeio direto, conclui: "A apropriação à unidade do produto de custos industriais, periódicos, nos mapas de custo, torna confuso - custeio de absorção para os administradores (managers) do nivel operacional, porque êstes custos unitários são válidos apenas para o volume e a composição da produção previstos" (tradução do autor). ${ }^{19}$

Esste ponto de vista encontra hoje aceitação generalizada. Os demonstrativos e relatórios de custo e resultados, em nivel setorial, são quase sempre demonstrativos da contribuição alcançada, pelo menos quando se trata de examinar um período curto, digamos de um mês até um ano.

Para períodos mais longos, a inclusão de custos fixos freqüentemente torna-se recomendável, porém as demonstreções financeiras dêsse tipo geralmente não se destinam ao contrôle de custos em nível operacional.

Os relatórios setoriais de uma fábrica são em geral reunidos e resumidos num demonstrativo para o nivel superior (por exemplo, destinado ao gerente da fábrica) onde as contribuições dos diversos setores são somadas e dali abatidos os custos do período (fixos) da fábrica. Neste tipo de relatório, a avaliação dos produtos prontos (ou intermediários), fabricados pelos diversos setores, procede-se por valôres-padrão. 0 exemplo, quadro 2, ilustra esquemàticamente um relatório dêsse tipo, de uma fábrica consistindo de dois setores. 0 supervisor de cada setor, neste caso, receberia um relatório individual que termina com a linha "Contribuição Total", demonstrando mais minuciosamente a composição dos custos diretos e as variâncias entre os custos reais e os orçados, de maneira que fica bem esclarecido o afastamento entre a contribuição real e a orçada. Essa análise ultrapassa os limites dêste artigo.

Outra forma do aproveitamento do custeio direto no nível operacional consiste em

\footnotetext{
17 Ver, por exemplo, Frye, D. Combined costing method: absorption and direct. Management Accounting, NAA N. Y. p. 18. jan. 1971.

18 Sóbre "custos controláveis" ver, por exemplo, Fremgen, J. M. Managerial cost analysis. Homewood, III., Irwin, 1966. p. 28.

10 Wright, W. Direct standard costs for decision marking and control. New York, McGraw-Hill, 1962. p. 184.
} 
expressar os dados relevantes (valor de vendas, contribuição e custos do período) em função dos custos-padrão diretos. A evolução mensal dos coeficientes obtidos é acompanhada sistemàticamente e interpretada para fins de contrôle administrativo. Esta idéia foi desenvolvida por $H$. C. Ford ${ }^{20}$ e fornece um excelente instrumento de contrôle.

Os comentários dêste item até agora referiam-se a demonstrações de resultados destinados ao nível médio ou seccional da emprêsa. A situação torna-se mais complexa quando se tratar de demonstrações financeiras que envolvem os custos e réditos da emprêsa inteira, destinadas ao uso da administração

superior ou até servindo para a publicação de resultados.

Para fins de informação gerencial e como base para decisões neste nível, há poucas dúvidas de que o custeio direto não sòmente fornece dados mais aproveitáveis como também que êstes dados são os únicos relevantes. A influência do método do custeio sôbre a apresentação do rédito e a sua composição é bem conhecida e foi objeto de inúmeras publicações da literatura especializada. W. Schoeps, no artigo inicialmente mencionado, apresenta um exemplo mostrando como o mesmo lucro total aparece em diferentes períodos devido à diversidade dos métodos de custeio. ${ }^{21}$

QUADRO 2

Relatório de custos de setores de produção

\begin{tabular}{|c|c|c|c|c|c|c|c|}
\hline \multirow{3}{*}{$\begin{array}{l}\text { Matéria-prima p/unid. } \\
\text { Mão-de-obra direta } \\
\text { Custos indiretos da fa- } \\
\text { bricação, variáveis }\end{array}$} & \multicolumn{3}{|c|}{$\begin{array}{c}\text { Produto } \boldsymbol{A} \\
\text { Orcado } \\
\text { Real }\end{array}$} & \multicolumn{2}{|c|}{ Produto $B$} & \multicolumn{2}{|c|}{ Total } \\
\hline & $\begin{array}{l}\mathrm{Cr} \$ \\
\mathrm{Cr} \$\end{array}$ & 3,00 & 3,00 & 6,50 & 6,00 & 一 & - \\
\hline & $\mathrm{Cr} \$$ & 1,20 & 1,30 & 3,30 & 3,00 & - & - \\
\hline $\begin{array}{l}\text { Custo de produção va- } \\
\text { riável, por unidade } \\
\text { Valor-padrão, p/unid. } \\
\text { Contrib. marginal } \\
\text { Contribuição, em }\end{array}$ & $\begin{array}{r}\mathrm{Cr} \$ \\
\mathrm{Cr} \$ \\
\mathrm{Cr} \$ \\
\%\end{array}$ & $\begin{array}{l}6,20 \\
10,00 \\
3,80 \\
38\end{array}$ & $\begin{array}{c}6,50 \\
10,00 \\
3,50 \\
35\end{array}$ & $\begin{array}{c}14,00 \\
20,00 \\
6,00 \\
30\end{array}$ & $\begin{array}{c}13,00 \\
20,00 \\
7,00 \\
35\end{array}$ & $\underline{-}$ & E \\
\hline $\begin{array}{l}\text { Quantidade produzida } \\
\text { (em unidades) } \\
\text { Contribuição total } \\
\text { Custos fixos das linhas } \\
\text { de produtos }\end{array}$ & $\begin{array}{l}\mathrm{Cr} \$ \\
\mathrm{Cr} \$\end{array}$ & $\begin{array}{r}5.000 \\
19.000\end{array}$ & $\begin{array}{r}4.600 \\
16.100 \\
3.000\end{array}$ & $\begin{array}{l}1.500 \\
9.000 \\
4.800\end{array}$ & $\begin{array}{r}1.600 \\
11.600 \\
5.000\end{array}$ & $\begin{array}{r}\overline{28.000} \\
7.900\end{array}$ & $\begin{array}{r}\overline{27.300} \\
8.000\end{array}$ \\
\hline Resultado bruto & Cr\$ & 15.900 & 13.100 & 4.200 & 6.200 & 20.100 & 19.300 \\
\hline Custos fixos da área de & rodus & ão, não & separáve & & & 5.000 & 5.100 \\
\hline Resultado da área de pr & dução & & & & & 15.100 & 14.200 \\
\hline
\end{tabular}

O assunto da aplicação do custeio direto é exaustivamente tratado por J. Sizer que examina as várias conseqüências para relatórios internos e externos. ${ }^{22}$ Todos os autores são unânimes em afirmar que as distorções causadas pelo custeio integral na análise de custos e réditos fazem com que os relatórios redigidos em base do custeio direto tornem-se preferíveis. No custeio integral, a relação custo-volume-lucro fica deformada em conseqüência da imputação e diluição dos custos fixos. A dificuldade na aceitação geral do procedimento do custeio direto consiste em que os relatórios financeiros se refletem nas publicações oficiais dos resultados, e o público e mormente os órgãos fiscalizadores privados (bancos, institutos de crédito) ou estatais, autoridades financeiras, bôlsas etc. mostram-se ainda céticos em aceitarem a nova interpretação.

Os quadros 3 e 4 ilustram um caso real em que as diferenças resultam da aplicação dos dois métodos de custeio no demonstrativo anual de uma emprêsa que fabrica três linhas de produtos. No primeiro caso, o do custeio integral (quadro 3), seguindo uma forma ainda muito em uso nas emprêsas do País, o custo fixo da área de produção foi apropriado, por um dos métodos usuais de cálculo, ao custo dos produtos fabricados e vendidos (não houve alteração de inventário) enquanto que os custos fixos da área administrativa foram apropriados às três linhas em proporção ao valor de vendas. Desta maneira, aparece um rédito relativamente baixo $(5,4 \%)$ da linha $A$, enquanto que o rédito percentual das outras linhas (duas) é mais de três vêzes superior. 0 retôrno sôbre o investimento, considerado como índice mais importante da rentabilidade, é igualmente baixo para os produtos da linha $A$, em confronto com os outros.

Recalculados os resultados em têrmos do custeio direto (quadro 4), verifica-se que, ao contrário do que foi mostrado anteriormente, a linha A é a maior contribuinte para a formação do lucro da emprêsa. O custo dos produtos vendidos compõem-se exclusivamente de custos variáveis nesta

apresentação e todos os custos fixos são deduzidos da contribuição total. Nada menos do que $63 \%$ desta contribuição é fornecida pela linha A, a qual se transforma, desta forma, em maior produtora de lucro. No caso em epigrafe, a reformulação do demonstrativo anual, em função da contribuição, teve

\footnotetext{
20 Ford, H. C. Ratios to standard direct cost. Management Accounting, NAA, New York, p. 35, jan. 1968.

21 Schoeps, W. op. cit. p. 63 e seg. $\approx$ Slzer, J. An insight into management accounting. Harmondsworth, England Penguin, 1969. p. 254 e seg.
} 
QUADRO 3

Exemplo de um relatório de custos e resultados usando custeio integral

Ano 1970

Em Cr $\$ 1.000$

\begin{tabular}{|c|c|c|c|c|c|c|c|c|c|}
\hline \multirow[b]{2}{*}{$(-)$} & \multirow[b]{2}{*}{$\begin{array}{l}\text { Faturamento (sem IPI) } \\
\text { Despesas diretas Vendas }\end{array}$} & \multicolumn{2}{|c|}{$\underset{\text { Cr\$ }}{\operatorname{Linha}} \underset{\mathscr{\mathscr { C }}}{\boldsymbol{A}}$} & \multicolumn{2}{|c|}{$\underset{\operatorname{Cr} \$}{\operatorname{Linha}} \underset{\mathscr{G}}{B}$} & \multicolumn{2}{|c|}{$\underset{\operatorname{Cr} \$}{\operatorname{Linha}} \underset{\mathscr{T}}{C}$} & \multicolumn{2}{|c|}{$\mathrm{Cr}^{\text {Total }} \%$} \\
\hline & & $\begin{array}{l}8.250 \\
1.850\end{array}$ & $\begin{array}{r}100,0 \\
22,5\end{array}$ & $\begin{array}{r}2.530 \\
\mathbf{5 3 0}\end{array}$ & $\begin{array}{r}100,0 \\
21,0\end{array}$ & $\begin{array}{l}690 \\
140\end{array}$ & $\begin{array}{r}100,0 \\
20,3\end{array}$ & $\begin{array}{r}11.470 \\
2.520\end{array}$ & $\begin{array}{r}100,0 \\
22,0\end{array}$ \\
\hline \multirow{2}{*}{$(-)$} & \multirow{2}{*}{$\begin{array}{l}\text { Receita liquida } \\
\text { Custo Prod. Vendas, integral } \\
\text { Custo Administracăo e Dis- } \\
\text { tribuição }\end{array}$} & $\begin{array}{l}6.400 \\
4.740\end{array}$ & $\begin{array}{l}77,5 \\
57,4\end{array}$ & $\begin{array}{l}2.000 \\
1.160\end{array}$ & $\begin{array}{l}79,0 \\
45,8\end{array}$ & $\begin{array}{l}550 \\
300\end{array}$ & $\begin{array}{l}79,7 \\
43,5\end{array}$ & $\begin{array}{l}8.950 \\
6.200\end{array}$ & $\begin{array}{l}78,0 \\
54,0\end{array}$ \\
\hline & & 1.210 & 14,7 & 370 & 14,7 & 100 & 14,7 & 1.680 & 14,7 \\
\hline & $\begin{array}{l}\text { Rédito operacional } \\
\text { Capita! investido } \\
\text { Retorno s/investimento }\end{array}$ & $\begin{array}{r}450 \\
3.000\end{array}$ & $\begin{array}{r}5,4 \\
15,0\end{array}$ & $\begin{array}{l}470 \\
900\end{array}$ & $\begin{array}{l}18,5 \\
52,0\end{array}$ & $\begin{array}{l}150 \\
400\end{array}$ & $\begin{array}{l}18,5 \\
38,0\end{array}$ & $\begin{array}{l}1.070 \\
4.300\end{array}$ & $\begin{array}{r}9,3 \\
25,0\end{array}$ \\
\hline
\end{tabular}

QUADRO 4

Exemplo de um relatório de custos e resultados usando custeio direto

Ano 1970

Em Cr\$1.000

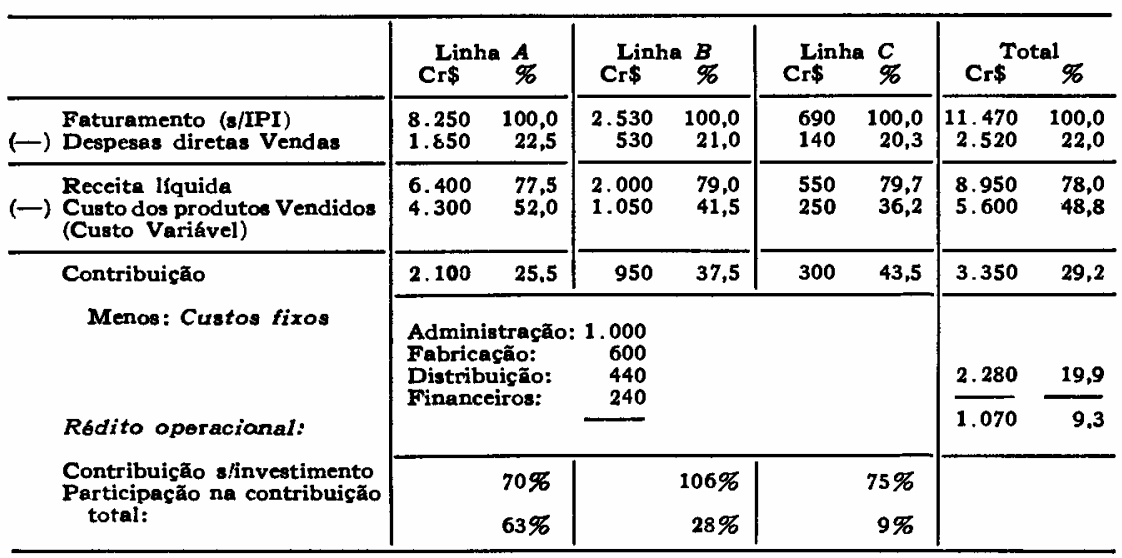

influência decisiva na política de investimento da emprêsa.

Um aspecto similar do custeio direto refere-se à decisão relativa ao problema da descontinuação de um segmento (linha de produtos, área de vendas, etc.) da emprêsa industrial, o qual, aparentemente, em base dos cálculos convencionais, está apresentando prejuízo. Substituindo o critério do lucro pelo da contribuição marginal, torna-se óbvio que o produto ou segmento crítico deve continuar enquanto essa contribuição fôr positiva, independentemente do lucro calculatório. Esta afirmação é válida, pelo menos, enquanto a emprêsa não encontrar outra atividade mais rendosa para suplantar a de baixa rentabilidade. Os princípios básicos dêsse critério decisório foram expostos por
Ivan Pinto Dias, em artigo publicado nesta revista. ${ }^{23} \mathrm{~J}$. Patterson explica como o critério pode ser aplicado, em um caso prático, para reorientar as decisões de uma emprêsa afetando a rentabilidade de linhas de produtos e de territórios do mercado. ${ }^{24} \mathrm{Em}$ decisões dêsse tipo, o critério da contribuição marginal é hoje

universalmente aceito.

A técnica do custeio direto também se aplica com vantagem em todos os casos em que se torna necessário determinar a maior lucratividade do emprêgo de um fator escasso de produção. Como fator escasso entende-se, por exemplo, tempo limitado de funcionamento de uma máquina, capacidade restrita de equipamentos (indústria química), falta de mão-de-obra especializada, falta de capital para giro ou qualquer outro fator de estrangulamento. Em todos êstes casos, a decisão relativa ao melhor aproveitamento do fator escasso será tomada em função da contribuição marginal por unidade do fator. Não é o rédito total (ou o custo total) que constitui o critério relevante, já que os custos fixos respectivos não devem entrar em cogitação. ${ }^{25}$ Esta maneira de raciocinar nas situações descritas não encontra hoje oposição.

A idéia de maximizar a contribuição de todos os fatôres da produção, escassos ou não, significa uma extensão do princípio para todo 0 planejamento da produção e vendas e foi exposta por $H$. Boehm \& F. Wille, mas, apesar de surtir grande interêsse entre os teóricos, a aplicação na prática dessa idéia ainda não se realizou em maior escala. ${ }^{2 a}$

Considerando que, em nosso meio, o capital representa geralmente um dos fatôres de maior grau de escassez, provàvelmente seria interessante substituir, nas análises financeiras, o índice do "Retôrno sôbre o Investimento" (computado como quociente: lucro/investimento) pelo quociente: "contribuição marginal/investimento", para fins de decisões sôbre a otimização do emprêgo de fundos.

Finalmente, nas análises de custos e resultados, executadas: por métodos quantitativos, os custos fixos são quase sempre

\footnotetext{
23 Dias, Ivan Pinto. Algumas observaçðes sôbre a margem de contribuição. Revista de Administraçăo de Empressas, (24): 90 e seg. 1967.

24 Patterson, J. R. Decision making applications of direct costing information. Management Accounting, NAA, New York, D. 11, jan. 1968.

26 Ver, por exemplo, Smith, C. \& Wille, A. The application of marginai costing. Management Accounting, ICWA, London, D. 170, abr. 1969.

: Boehm, H. \& Wille, F. Deckungsbeitragsrechnung und Optimierung. Munich, Verl. Moderne Industrie, 1967.
} 
considerados como irrelevantes. A técnica da programação matemática, quando empregada nesta área, opera

exclusivamente com os dados do custeio direto, ${ }^{27}$ o mesmo acontecendo na sistemática do PERT/Custo, o qual normalmente abandona os custos fixos antes de indicar a solução.

Um desenvolvimento mais recente na aplicação do custeio direto em demonstrações do resultado financeiro foi introduzido por K. Agthe, ${ }^{28} \mathrm{e}$ consiste na apropriação gradativa de custos fixos "separáveis" aos custos de linhas de produtos, grupos de linhas, segmentos, divisões da emprêsa e assim por diante, em escala ascendente até permanecer um resto de custos fixos gerais, indivisíveis, da emprêsa inteira. Em cada degrau da escala determina-se sua contribuição para a cobertura dos custos do segmento superior. $O$ quadro 5 mostra o procedimento em forma esquemática.

Os proponentes dêste sistema consideram que determinados custos que são fixos para um nível inferior da hierarquia adquirem certa variabilidade quando vistos pelo nível superior. Realmente, muitos custos fixos tornam-se variáveis no sentido de ficarem "evitáveis" no momento em que - setor inteiro da emprêsa deixa de funcionar. Este argumento, embora lògicamente correto, é difícil de ser comprovado na prática empresarial. Entretanto, o método está encontrando crescente aplicação na análise do custo de distribuição.

\section{QUADRO 5}

Apropriação gradativa do custos fixos

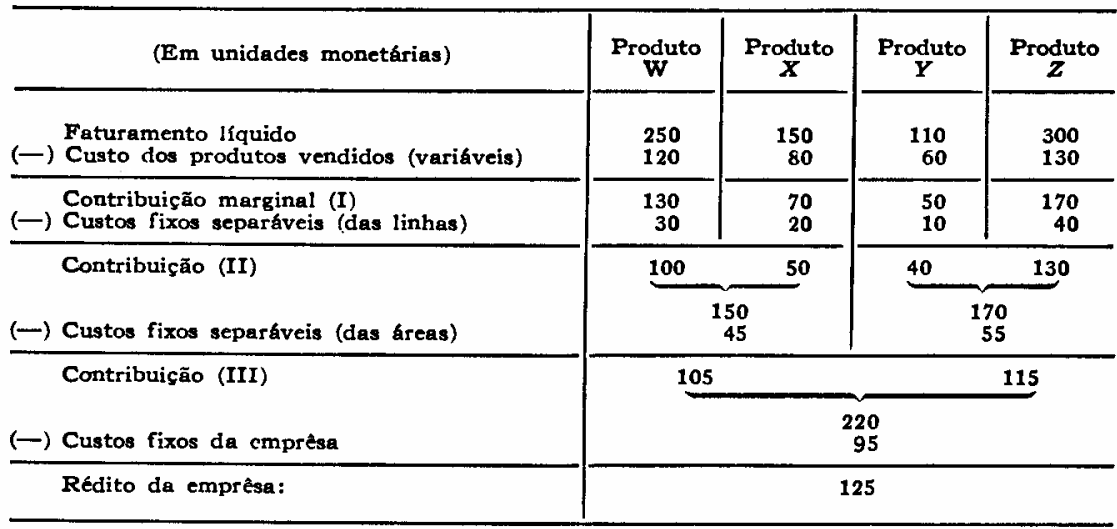

Um grupo de especialistas, que geralmente encara o sistema do custeio direto em grandes restrições, são os analistas do mercado de capitais.

Acostumados como são a analisar os demonstrativos financeiros das emprêsas em têrmos dos conhecidos índices de lucratividade, ou de liquidez, etc., duvidam êles que êstes índices, quando calculados com base em relatórios de custeio direto, mostrarão o mesmo comportamento de antes. Esta opinião parece válida quando se cotejam os índices de várias emprêsas, das quais uma parte opera no sistema convencional de custos enquanto a outra emprega o sistema nôvo.

No momento porém em que tôdas elas fizessem uso do custeio direto, a sua posição relativa no ranking, formado pelos índices geralmente usados, não diferiria significativamente do ranking que seria obtido partindo da forma tradicional dos demonstrativos financeiros. Um estudo interessante que comprova esta afirmação foi recentemente publicado por D. Sharp, ${ }^{29}$ usando um modêlo de simulação envolvendo 25 emprêsas do ramo da indústria química. De qualquer forma, a maior ou menor facilidade de interpretação das demonstrações de resultados por parte dos analistas de investimentos não devia ser em si argumento decisivo para a adoção de um sistema determinado de apresentação dos custos.

Tendo em vista as considerações desenvolvidas, não é muito surpreendente que grande número de companhias sirva-se dos princípios do custeio direto ao menos para seus relatórios internos, devotados a fornecerem informações para a administração e suas decisões. J. Sizer afirma categòricamente que "o custeio marginal é a técnica mais útil para a tomada de decisões nas emprêsas de produção" (tradução do autor). ${ }^{30}$ Acreditamos que a maioria dos administradores modernos já se convenceram dêste fato e exigem que as informações financeiras sôbre resultados sejam apresentadas em têrmos do custeio direto. Quanto aos teóricos, que tratam do valor informativo de demonstrações financeiras para o processo da tomada de decisões, já há mais tempo que dão preferência absoluta ao sistema do custeio direto, como já afirmou L. Doyle no ano de $1954 .{ }^{31}$

\footnotetext{
27 Uma boa exposição de metodologia da programação linear aplicada em conjunto com as diversas técnicas do custeio direto encontra-se em: Moews $D$. Zur Aussagefaehigkeit neuer Kostenrechnungsverfahren. Berlin, Dunker \& Humbolt, 1969, p. 103 e seg.

28 Agthe, K. Stufenweise Fixkostendeckung in System des Direct Costing. Zeitschrift fuer Betriebwirtschaft. Wiesbaden, set. 1959. p. 404.

20 Sharp, D. The effect of direct costing on the relative size of financial ratios. Management Accounting, NAA New York, p. 14, nov. 1970.

so Sizer, J. op. cit. p. 273.

31 Doyle, L. In: NA(C)A Bulletin, New York, p. 1.582, agô. 1954.
} 


\section{A DETERMINAÇAO DO PRECCO DE VENDA PELO CUSTEIO DIRETO}

Em nenhuma área a polêmica a respeito do método do custeio direto é tão acirrada como na problemática da formação, pela emprêsa, dos preços de venda de seus produtos. Esta discussão, aliás, faz parte de uma divergência mais ampla a respeito da questão, entre economistas e contadores, como muito bem demonstraram $W$. T. Baxter \& A. R. Oxenfeldt em um artigo, hoje muito difundido. ${ }^{32}$ Os economistas afirmam, nas teorias clássicas da formação de preços, que êstes são conseqüências da interação entre custos, demanda e outros fatôres do mercado e que a firma, tentando maximizar o rédito, pode achar a combinação do preço e do nível de vendas que melhor consegue êste objetivo.

Os contadores, por sua vez, coletam, manipulam e analisam os custos da emprêsa, e, adicionando o lucro, chegam aos preços por métodos rotineiros de cálculo.

Para usar a teoria dos economistas, a emprêsa necessitaria ter conhecimentos amplos sôbre a função demanda-preços, o que na realidade quase nunca ocorre, de maneira que esta interpretação não resolve a questão. ${ }^{33} \mathrm{~A}$ concepção dos contadores, por outro lado, do cálculo do preço em dados estritamente internos da emprêsa presume que esta possui liberdade de fixar os preços de seus produtos a seu critério. Esta liberdade, na prática, também não existe, já que ela está severamente limitada pelas condições do mercado. Neste ponto, os economistas têm um argumento válido.

0 método do custeio direto tem como característica particular a capacidade de conciliar os dois pontos de vista, usando de um lado os dados de custo como base da determinação de preços, mas permitindo bastante flexibilidade na fixação do preço definitivo para atender aos fatôres do mercado. Em vez de procurar maximizar - rédito, ou fixar uma margem rígida de lucro, o apreçamento pelo custeio direto procura obter um rédito satisfatório. A dificuldade da aplicação do princípio reside justamente na definição prévia do que constitui rédito satisfatório, seja êste definido como um retôrno sôbre o investimento, preestabelecido, ou em têrmos de expansão da emprêsa, etc. Examinaremos êste aspecto mais adiante; por ora procuraremos esclarecer as diferenças básicas na determinação do preço pelos dois sistemas de custeio.

0 procedimento pelo custeio total é suficientemente conhecido: começa-se com o cálculo do custo de produção do artigo e, adicionando as respectivas parcelas do custo administrativo e do custo de distribuição, obtém-se, como somatório, o custo total (integral) do produto. A êste é agregado uma margem de lucro para obter o preço de venda. Em tôdas as parcelas de custo mencionadas, de produçãa, administração e distribuição, encontramos custos diretos e indiretos e, nestes últimos tanto os fixos como os variáveis, de maneira que, pelo menos em teoria, todos os custos da emprêsa foram apropriados ao produto. $O$ lucro calculado deve ser interpretado como lucro líquido da venda do artigo.

Procedendo pelo custeio direto somam-se: os custos variáveis da produção e os custos variáveis da distribuição, obtendo-se como resultado 0 .

\footnotetext{
32 Baxter, W. \& Oxenfeldt, A. R. Costing and pricing: the cost accountant versus the economist. Studies in cost analysis. D. Solomons, London, Sweet \& Maxwell, 1968, p. 293.

* Anthony, R. \& Hekimian. Operations cost control. Homewood, III., Irwin, 1967. p 131. Afirmam estes autores a respeito "... os complexos diagramas e equaçбes construidos pelos economistas não podem ser usados para solucionar os problemas do preço do mundo real..." (traduçáo do autor).
} 
custo direto do produto. A êste adiciona-se a margem de contribuição para chegar ao preço de venda. No custo direto, que na realidade é um custo parcial, nenhum custo fixo está representado.

Resumindo:

Custeio integral: Custo total + + lucro $=$ preço

Custeio direto: Custo variável + + contribuição $=$ preço

(Ver exemplo do quadro 6).

\section{QUADRO 6}

Cálculo do custo e do preço de um produto industrial

a) Custeio integral:

Matéria-prima: $10 \mathrm{~kg}$ a $\mathrm{Cr} \$ 4,00 / \mathrm{kg}$

Mão-de-obra direta (incl. encargos): 18 horas a $\mathrm{Cr} \$ 2,00 / \mathrm{h}$

Custos indiretos da fabricação: $\mathbf{C r} \$ \mathbf{3 , 0 0}$ por hora aplicada (fixos e variáveis)

Soma: Custo de produção (CP) (para avaliação inventarial)

Custo administrativo (20\% do CP) (indireto, fixo)

Custo da distribuiçăo ( $10 \%$ do CP) (indireto, fixo)

Custos diretos da venda (25\% do preço) $(\mathrm{ICM}=17 \%$, Comissões $=5 \%$, Desconto $=3 \%)$

Soma: Custo total (limite inferior do preço)

Margem de lucro: (15\% do preço, preestabelecida)

Preço de venda

b) Custeio direto:

Matéria-prima: $10 \mathrm{~kg}$ a $\mathrm{Cr} \$ 4,00 / \mathrm{kg}$

Mão-de obra direta: 18 horas a $\mathrm{Cr} \$ 2,00 / \mathrm{h}$

Custos indiretos da fabricação: Cr\$ 1,00/hora aplicada, (variáveis)

Soma: Custo de produção (direto) (para avaliação inventarial)

Custos diretos da venda: (25\% do preço)

Soma: Custo direto do produto (limite inferior do preço)

Margem de contribuiçâo:

Preço de venda:

Cr\$ 40,00

36,00

54,00

Cr $\$ 120,00$

24,00

12,00

65,00

Cr\$221,00

39,00

Cr $\$ 260,00$

Cr $\$ \quad 40,00$

36,00

$\$ 18,00$

Cr\$ 94,00

65,00

Cr $\$ 159,00$

101,00

Cr $\$ 260,00$

Ambos os procedimentos da formação do preço possuem dificuldades inerentes para as quais aparentemente não foram encontradas soluções

completamente satisfatórias.

Parece, porém, que as

dificuldades, no caso do

custeio direto são tècnicamente mais suscetiveis de uma solução objetiva que no outro caso.

As dúvidas relacionadas com o custeio integral nascem de duas direções: primeiro, a apropriação dos custos fixos ao produto é feita mediante coeficientes de rateio ou chaves similares, de caráter altamente arbitrário, cujos valôres dependem do método de cálculo escolhido. Desta forma, o custo total acima é resultado de um processo inseguro, mal definido ${ }^{34} \mathrm{e}$, em conseqüência, não é merecedor de muita confiança. Êste aspecto foi ventilado na literatura técnica até o ponto de saturação, com muitos autores procurando estabelecer critérios de apropriação para os custos fixos por êles considerados superiores aos demais. Não pretendemos aqui entrar no mérito da questão; resta apenas a constatação de que os progressos realizados neste sentido são diminutos. 0 segundo fator que causa transtornos é o fato de que alterações no nível da atividade refletem-se nas parcelas do custo fixo apropriado, e conseqüentemente, no preço calculado. Porém, dêste último, por sua vez, depende o nivel de vendas, de forma que a relação custo-preço entra em raciocínio circular. ${ }^{35}$

A dificuldade particular na aplicação do custeio direto para a determinação do preço está ligada ao seguinte problema: nos dois sistemas de custeio o preço é obtido por adição de um complemento ao custo; do lucro no custeio integral e da contribuição no custeio direto. Em ambos os casos surge a pergunta: qual deve ser a taxa dêste complemento? A resposta torna-se mais fácil no caso do lucro. Existem praxes tradicionais em vários ramos industriais ou simplesmente hábitos de longos anos que estipulam determinadas percentagens para a margem de lucro, por exemplo 10, 15 ou $20 \%$ e estas taxas estão sendo aplicadas sem maiores ponderações.

Há, naturalmente muitas firmas que planejam êste lucro mais cuidadosamente, mas, em todo caso, o risco de errar na escolha da taxa adicional de lucro não é tão grande; na pior das hipóteses deixa-se de ganhar um rédito positivo. A situação é bem diferente no custeio direto. A margem de contribuição deve ser bastante elevada para cobrir todos os custos fixos e ainda fornecer um rédito positivo. Neste caso é óbvio que um êrro substancial pode provocar conseqüências mais graves. Uma margem de contribuição muito baixa pode provocar não sòmente a ausência de qualquer lucro como também o aparecimento de um prejuízo considerável em virtude da eventual insuficiência da contribuição para cobrir os custos fixos. Enfocado sob êste aspecto, o sistema do custeio direto apresenta-se como de índole muito mais especulativa em comparação ao custeio

24 Para uma demonstração simples deste fato, ver, por exemplo, Hansen, P. Contabilidad interna de la industria. Madrid, Aguilar, 1957. p. 294 e seg.

ss Ver também Shilliglaw, G. Op. cit. p. 686. 
integral. ${ }^{36}$ Este argumento não deve ser menosprezado; na mão de um administrador de competência limitada a formação do preço pelo custeio direto é capaz de pôr em perigo a estabilidade empresarial. A amplitude da margem de contribuição é muito maior que a do lucro; margens de $30 \%$ a $40 \%$ não são raras.

Inversamente o chamado "Limite Inferior do Preço", constituído no primeiro caso pelo custo total do produto, é mais alto do que no segundo caso onde êle é constituído pelo custo direto do produto, fato êste que confere ao custeio integral mais segurança contra preços calculados tão baixos que dão prejuízos.

Para garantir-se contra o uso em escala maior de margens insuficientes de contribuição existe, entretanto, um procedimento que elimina os riscos especulativos. Trata-se do planejamento ou orçamento completo do rédito. ${ }^{37} \mathrm{Nas}$ emprêsas conduzidas por métodos modernos, êste planejamento sempre é encontrado, independentemente do método de custeio utilizado, fazendo, parte da sistemática do planejamento ou orçamento geral. Partindo de um dado básico, como por exemplo, do capital médio investido durante o período projetado e o retôrno esperado sôbre êsse capital, estipula-se um montante total da contribuição a ser alcançada. 0 próximo passo é a distribuição dêsse total sôbre os diversos produtos, empregando-se geralmente taxas diferentes, de acôrdo com as possibilidades dos produtos ou das linhas no mercado. É perfeitamente admissível que algum produto seja calculado com uma margem de contribuição relativamente muito baixa em confronto com outros; o essencial é que fica garantida a contribuição total da firma. Esta possibilidade de diferenciação das margens empresta ao sistema do custeio direto uma flexibilidade muito maior na formação de preços e constitui uma das suas vantagens mais importantes. I. Gergely denomina essas taxas diferenciadas de "contribuições específicas de cobertura" e demonstra sua aplicação no cálculo na indústria de máquinas. ${ }^{38}$

\section{Comparando as dificuldades} da aplicação do custeio direto para a determinação do preço com a arbitrariedade introduzida pelo custeio integral, conclui-se que as primeiras são venciveis enquanto que a última não pode ser eliminada; conseqüentemente, dever-se-ia optar pelo sistema de custeio direito para a finalidade aqui citada. Porém, muitos

teóricos e ainda maior número de práticos na administração empresarial, especialmente os contadores tradicionais, ainda repelem o sistema do custeio direto para a determinação do preço, alegando que tal sistema não oferece bastante segurança, ou então, sustentando a opinião de que o conhecimento da lucratividade, ou seja, da margem de lucro líquido dos produtos é essencial. Herson \& Hertz, após analisar cuidadosamente 0 assunto, chegam a conclusão de que "uma política de preços baseada no custeio direto não é realística porque deixa de estabelecer uma margem de lucro mínima que pode ser usada pela administração a fim de comparar a lucratividade relativa dos produtos..." (tradução do autor). ${ }^{39}$ Esta citação espelha muito bem a atitude clássica. A concepção moderna refuta a lucratividade relativa na produção múltipla, como uma ficção resultante de um artifício aritmético que é a imputação calculatória dos custos fixos.

Outra corrente que também apóia o preço formado pelo custeio total é a dos adeptos da idéia de um "preço justo", ou seja, do preço formado mediante uma taxa de lucro razoável e limitada, socialmente justificável, que protege 0 comprador contra a "exploração" pelo vendedor ou produtor. Esta idéia, que aliás não pertence mais ao campo da análise econômica, não possui fundamento prático. C. Gillespie, adotando esta argumentação, qualifica o preço justo como uma "noção medieval". ${ }^{40}$ Contudo, ela persiste no pensamento de vários organismos governamentais de contrôle de preços em muitos países que lutam contra a inflação e tentam proteger o consumidor através da fixação de uma taxa limitada de lucro a ser adicionada ao chamado "custo genuíno". Para computar êsse custo genuíno montam-se esquemas complicados de cálculo que estendem o conceito de custo total até o limite. Não se conhecem estudos publicados que examinem o emprêgo do custeio direto para fins de contrôle de preços pelo estado, mas há poucas dúvidas de que, para o acompanhamento da evolução dos custos e para a comparação dos custos de diversos produtores $e$ de diferentes épocas, êsses órgãos tirariam melhor proveito utilizando a técnica direta.

Quanto à aplicação prática do custeio direto para a formação de preços, é interessante notar que êle se encontra quase universalmente aceito no cálculo do comércio varejista, em supermercados, grandes magazines, etc. Este fato deu um grande impulso à difusão geral do sistema, como foi observado por Boehm \& Wille. ${ }^{41}$ Realmente, a técnica de calcular

* Ver Herson, R. Hertz, R. Direct

costing in princing, a critical reappraisal. In: Management Services, New York, (2): 38, 1968.

s7 Para um bom estudo dêste aspecto, ver: Mizouguchi, K. Dlrect costing und Preisbestimmung. In: Zeitschrift fuer betriebs - wirtschaftliche Forschung Colonia, (2-3): 123, 1969.

a Gergely, 1. Die

Deckungs beitragsrechnung als

Grundlage von Preis kalkulationen Im Maschinenbau. Kostenrechnungspraxis, Wiesbaden, (3): 101, 1966.

se Herson, R. \& Hertz, R. art. cit. p. 42. 0 Gillespie, C. Standard and direct costing. Englewood, N. J., Prentice Hall, 1962. p. 654.

11 Boehm, H. \& Willie, F. Direct costing y su relación con la programación de la gestion. Madrid, Sagitario, 1965, p. 89. 
os preços de vendas dos artigos partindo do custo de aquisição e acrescentando uma margem bruta (gross margin ou mark-up) não é nada mais do que a aplicação dos princípios do custeio direto. A técnica é superior ao método antigo que distribuía os custos operacionais das lojas sôbre os produtos, usando processos burocráticos complicados, no intuito de apurar o rédito líquido de venda. Em lojas departamentais o o custeio direto encontra uma outra forma de utilização de definição mais ampla. Em lugar de produtos individuais, são os setores mercadológicos dos departamentos (seções, linhas, etc.) que são considerados como portadores de custo aos quais se atribui as parcelas identificáveis (separáveis) das despesas. Desta forma apura-se uma contribuição de segundo nível para cada departamento que permite julgar a sua rentabilidade. Partindo de análises dêsse tipo, o conceito do custeio direto expandiu-se para a área industrial. 42

O problema da determinação de preços naturalmente não é limitado aos diversos aspectos do custeio e do método de cálculo. Entram em jôgo muitos outros fatôres econômicos e calculatórios, ${ }^{43}$ além de uma boa dose de elementos qualitativos como questões de sortimento, ambição no mercado e finalmente a intuição empresarial. Querer limitar o dilema da formação de preços à mera alternativa entre sistemas de custeio parece ser um ângulo demasiadamente estreito.

\section{OUTROS ASPECTOS DA APLICAÇAOO DO CUSTEIO DIRETO}

Além destas três áreas examinadas, encontramos várias outras áreas onde 0 custeio direto é empregado com crescente vantagem.

Entre elas, a primeira que deve ser citada é a da programação da produção industrial e contrôle da execução dos programas. Muitos autores, especialmente na Alemanha, neste caso, ligam o contrôle pelo método do custo-padrão com a planificação em base do custeio direto

(Grenzplankosten). ${ }^{44}$ Esta sistemática está encontrando cada vez mais receptividade nos outros países industriais;

indiscutivelmente a combinação mencionada fornece um excelente instrumento de gestão das emprêsas industriais ${ }^{40}$ e efetivamente não existem dúvidas a respeito de seus aspectos teóricos. $\mathrm{Na}$ prática encontramos certa relutância devido ao maior grau de complexidade introduzido. No Brasil, a situação inflacionária ainda cria um certo ceticismo perante tôdas as técnicas contábeis que operam com custos e preços estandardizados.

Um problema, já antigo, que se torna mais acessivel ao tratamento pelo custeio direto é o do preço de transferência. ${ }^{\mathbf{4 6}}$ Sempre que ocorrem transferências de produtos ou serviços entre divisões de uma corporação ou entre

departamentos com maior grau de autonomia da mesma emprêsa, surgem discussões sôbre o preço a ser atribuído a êsses fornecimentos. E claro que o preço de transferência influirá decisivamente no rédito das divisões, repercutindo sôbre os investimentos autorizados pela cúpula e sôbre o status dos responsáveis por essas decisões. Havendo, como sempre há, interêsses conflitantes, o preço é difícil de se fixar. $O$ custeio direto não é uma panacéia e seu emprêgo nos casos em foco não dirime completamente as dúvidas, mas, uma vez aceito o princípio básico do custeio direto da exclusão dos custos fixos e do over-head central, as soluções para a determinação do preço de transferência tornam-se mais fáceis.
Um desenvolvimento mais recente, ao qual já foi feito alusão nos itens precedentes, é o da extensão do conceito do custo direto além da sua definição original que o limitou a um "determinado produto" (ver item 2). Substituindo o têrmo "produto" pelo conceito do "segmento", obtemos uma definição mais ampla do custo direto, ou seja, de todos os custos separáveis em relação ao segmento. A êste respeito C. Horngren observa o seguinte: "Para tomar decisões inteligentes o manager requer informações relevantes sôbre diversos objetivos. Elle procura o custo de algo: de um produto, de um departamento, de um grupo de produtos, de um território (de vendas), de uma divisão, de um processo ou de uma fábrica. Nós definimos êste algo como um segmento - ou seja, qualquer linha de atividade ou parte de uma organização para a qual uma computação separada de custos ou das vendas é procurada" (tradução do autor). ${ }^{47}$

Esta conceituação mais ampla do custeio direto, na qual $o$ produto, como "unidade de custo", está sendo substituído pelo segmento, possui grande utilidade em várias análises de custo e rédito, não apenas em emprêsas comerciais, como já

(3) Ver, por exemplo, Longman, D. \& Schiff, M. Practical distrition cost analysis. Homewood, III., Irwin, 1955.

4 Para uma boa exposiçăo do problema, ver: Nickerson, C. Managerial cost accounting and analysis. McGraw-Hill, 1962. p. 544.

4 Por exemplo, Boehm, H. \& Wille, F. op. cit. que $e$ quase completamente dedicada a essa técnica, como também várias outras obras dos mesmos autores, ou Schwartz, H. Kostentraegerrechnun und Unternehmungsfuehrung. Berlin.
Herne, 1969, p. 40 e seg.

15 Ver Fahey, B. Production performance reporting under direct costing. Management Accounting, NAA, p. 9, nov. 1970.

4 o assunto foi exposto por $\rfloor$. Hirshleifer em um artigo que se tornou bem conhecido, publicado em 1956: On the economics of transfer pricing reproduzido In: Modern financial management. B. V. Carsberg \& H. C. Edey, Harmondsworth, England, Peguin, 1969. p. 46. Na mesma edição ver também: Gould, J. R. Internal pricing in firms. p. 265.

i7 Horngren, C. Cost accounting, a managerial emphasis. Englewood, N. J. Prentice Hall, 1967. p. 299. 
foi mencionado, mas também na análise e contrôle dos custos de distribuição das emprêsas industriais. ${ }^{48} \mathrm{~A}$ técnica de apropriar gradativamente os custos fixos, em escala ascendente, como descrita no item 4 dêste artigo, é de certa forma também uma separação de custos por segmentos.

Em muitos casos especiais, de decisões sôbre investimentos e desinvestimentos, da introdução de produtos novos e da descontinuação de produtos fabricados, os critérios baseados no cálculo pela margem de contribuição fornecem resultados muito mais corretos do que a tentativa de tomar a decisão mediante previsão do rédito líquido. Nesta área, que é totalmente extracontábil, os métodos do custeio direto dominam.

Há um aspecto do custeio direto que deve ser examinado cuidadosamente por tôdas as emprêsas que pretendem implantar o sistema. Trata-se das dificuldades que surgem na área da contabilização. 0 sistema do custeio direto implica a separação perfeita entre custos variáveis e custos fixos nos registros contábeis. $E$ indispensável que o plano de contas considere esta necessidade de tal forma que, desde o Indice, as despesas sejam escrituradas em contas específicas.

A prática tem demonstrado que são poucas as firmas preparadas para classificar contábilmente os custos sob o ponto de vista de sua variabilidade, especialmente quando surgem casos de despesas compostas de componentes fixos e variáveis (por exemplo, despesas de manutenção). Contudo, esta separação torna-se indispensável para um perfeito funcionamento do sistema. As emprêsas, que possuem uma contabilidade de custos e usam mapas de localização por centros de custos, dispõem geralmente de maiores facilidades neste sentido já que
- mapa de localização é um instrumento mais flexível que permite a separação dos dois grupos de custo nos próprios centros. 0 assunto de contabilização formal pelo custeio direto foi abordado em obra de P. Occhipinti, ${ }^{49}$ enquanto que $W$. Kilger expõe pormenorizadamente a técnica aplicada à análise por centros de custos e ao contrôle orçamentário. ${ }^{50}$ Estas dificuldades, da classificação das despesas por meios estritamente contábeis, são outro motivo que causa certa relutância entre os contadores profissionais perante os métodos do custeio direto .

Relacionado com o problema da classificação dos custos existe outro fenômeno que no futuro causará obstáculos maiores à introdução generalizada do sistema do custeio direto. 0 processo tecnológico em desenvolvimento da automatização das indústrias diminuirá cada vez mais a participação dos custos diretos e variáveis no custo total das emprêsas. 0 trabalho humano está sendo substituído pelo trabalho da máquina em escala crescente e o custo variável da mão-de-obra desaparece em favor do custo fixo da depreciação como elemento preponderante do custo. Até o custo da própria matéria-prima consumida, sempre considerada paradigma dos custos diretos e proporcionais, está sujeito a perder êste caráter nas indústrias de produção acoplada (produtos conjuntos). De qualquer forma, por um ou outro motivo, o montante global dos custos diretos tende a decrescer. No momento em que a contribuição marginal se aproxima ou ultrapassa a taxa de $50 \%$, as conclusões tiradas do sistema para fins decisórios perdem muito do seu valor informativo.

\section{CONCLUSÕES}

Resumindo os pontos principais desta exposição pode-se afirmar: a) O sistema do "custeio direto", o qual, corretamente, devia ser denominado "custeio variável", exclui os custos fixos do custo do produto ou, em sentido mais amplo, do custo da unidade de custo. Substitui o lucro pela contribuição marginal.

b) Para fins da avaliação da existência de produtos próprios das emprêsas industriais, 0 custeio direto é o único sistema que fornece valôres incontroversíveis. A introdução generalizada do sistema encontra empecilhos na resistência por parte das autoridades fiscais, devido ao impacto sôbre o rédito tributável.

c) 0 rédito demonstrado pelo custeio direto não sòmente é mais correto do que o rédito apurado pelos métodos tradicionais, como também sua formação é de mais fácil interpretação para fins administrativos e para a tomada de decisões. As demonstrações financeiras elaboradas de acôrdo com os critérios do custeio direto permitem conclusões mais claras e corretas.

d) No procedimento da determinação de preços por métodos calculatórios, 0 custeio direto permite maior flexibilidade. Os preços obtidos pelo sistema serão satisfatórios sòmente quando a emprêsa possuir um planejamento orçamentário em funcionamento. Para uma política de preços a longo prazo o custeio direto não pode substituir satisfatòriamente os preços à base do custo total.

e) Para decisões operacionais onde entra o fator custo e, especialmente, quando estas decisões são baseadas em métodos quantitativos, a contribuição substitui o rédito

¿8 Ver: Dobson, R. W. Distribution cost accounting. London, Gee \& Co., 1969.

- Occhipinti, P. op. cit.

so Kilger, W. Flexible Plankostenrechnung. Colonia, Westfaelischer Verlag, 1967. 
quase sempre como critério decisório.

f) A evolução futura da implantação do custeio direto, em que pêsem suas vantagens descritas, dependerá em larga escala da posição oficial e da possivel eliminação de certas dificuldades técnicas de escrituração e, finalmente, do desenvolvimento da tecnologia industrial. As modernas tendências da gestão de emprêsas, resumidas sob o título de "Ciência Gerencial" (Management Science), certamente contribuirão para dar maior amplitude ao emprêgo do custeio direto.

E vasto o programa editorial da UNESCO. No Brasil, êsse valioso acervo de obras, versando sôbre aspectos variados das atividades culturais, educacionais e científicas do homem, encontra-se à sua disposição na Fundação Getúlio Vargas, através do seu Serviço de Publicações, de suas livrarias ou de seus revendedores autorizados em todo o País.

Qualquer que seja o seu campo de atividade, solicite o catálogo de obras da UNESCO a qualquer uma das nossas livrarias ou a um dos nossos agentes de vendas autorizados.

LIVRARIAS:

Praia de Botafogo, 188

Caixa Postal, 21.120

Rio de Janeiro, GB

Avenida Graça Aranha, 26

Lojas $\mathrm{C}$ e $\mathrm{H}$

Rio de Janeiro, GB
Super Quadra 104 - Bloco A

Loja 11

Brasília, DF

Avenida Nove de Julho, 2029

Caixa Postal, 5534

São Paulo, SP

\section{AGENTES AUTORIZADOS:}

Dilertec

Distribuidora de Livros e Revistas

Ltda.

Rua Coelho Rodrigues, 1244

Teresina - PI

Ceará - Ciência e Cultura

Rua Edgard Borges, 89

Fortaleza, CE

Organização Sulina de Representaçōes

Av. Borges de Medeiros, 1030

Pôrto Alegre, RS

Catavento - Distribuidora de Livros

Ltda.

Rua Conselheiro Ramalho, 928

Tel.: 36-5642

São Paulo - SP

Fornecedora de Publicações Técnicas

M. M. de Oilveira Marques

Av. Ipiranga, 200 - Loja 40

São Paulo, SP

Livraria Martins

Av. Campos Sales, 171

Belém, PA

Lunardelli Representações

Livraria Universitária

Rua Vitor Meireles, 23-A

Florianópolis, SC
Centro do Livro Brasileiro

Rua Rodrigues Sampaio, 30-B

Lisboa, Portugal

Agência Van Damme

Rua Goitacazes, 103, s/1310

Belo Horizonte, MG

Livraria Ghignone

Rua Quinze de Novembro, 423

Curitiba, PR

Livraria Civilização

Brasileira S.A

Rua Padre Vieira, 9

Salvador, BA

M. Inojosa

Av. Dantas Barreto, 564

Sala 901

Recife, PE

Livraria J.C

Rua Nina Rodrigues, 33-B

São Luiz, MA

Praia Grande Distribuidora

Rua Tiradentes, 71

Loja 2

Ingá

Niterói, RJ

Ou pelo reembôlso postal. Pedidos para a Editôra da Fundação Getúlio Vargas. Praia de Botafogo, 188, C.P. 21.120, ZC 05, Rio de Janeiro, GB 